\title{
Observation and modeling of NPP for Pinus elliottii plantation in subtropical China
}

\author{
MA ZeQing ${ }^{1,3}$, LIU QiJing ${ }^{1,2 \dagger}$, WANG HuiMin ${ }^{1}$, LI XuanRan ${ }^{1,3}$, ZENG HuiQing ${ }^{4}$ \& XU WenJia ${ }^{1,3}$ \\ ${ }^{1}$ Institute of Geographic Sciences and Natural Resources Research, Chinese Academy of Sciences, Beijing 100101, China; \\ ${ }^{2}$ College of Forestry, Beijing Forestry University, Beijing 100083, China; \\ ${ }^{3}$ Graduate School of Chinese Academy of Sciences, Beijing 100049, China; \\ ${ }^{4}$ Research Center for Eco-Environmental Sciences, Chinese Academy of Sciences, Beijing 100085, China
}

Based on the stem analysis of 59 individuals of Pinus elliottii in combination with tree biomass models, we calculated annual biomass increment of forest plots at Qianyanzhou Ecological Station, Chinese Academy of Sciences in subtropical China. In addition, canopy layer and community NPP were calculated based on 12 years' litter fall data. NPP of the 21-year-old forest was estimated by using the BIOME BGC model; and both measured NPP and estimated NPP were compared with flux data. Community biomass was $10574 \mathrm{~g} \cdot \mathrm{m}^{-2}$; its distribution patterns in tree layer, shrub layer, herbaceous layer, tree root, herbaceous and shrub roots and fine roots were $7542,480,239,1810,230,274$ and $239 \mathrm{~g} \cdot \mathrm{m}^{-2}$, respectively. From 1999 to 2004 , the average annual growth rate and litter fall were $741 \mathrm{~g} \cdot \mathrm{m}^{-2} \cdot \mathrm{a}^{-1}$ $\left(381.31 \mathrm{gC} \cdot \mathrm{m}^{-2} \cdot \mathrm{a}^{-1}\right)$ and $849 \mathrm{~g} \cdot \mathrm{m}^{-2} \cdot \mathrm{a}^{-1}\left(463 \mathrm{gC} \cdot \mathrm{m}^{-2} \cdot \mathrm{a}^{-1}\right)$, respectively. There was a significant correlation between annual litter fall and annual biomass increment; and the litter fall was 1.19 times the biomass increment of living trees. From 1985 to 2005, average NPP and GPP values based on BGC modeling were $630.88\left(343.31-906.42 \mathrm{gC} \cdot \mathrm{m}^{-2} \cdot \mathrm{a}^{-1}\right)$ and $1800 \mathrm{gC} \cdot \mathrm{m}^{-2} \cdot \mathrm{a}^{-1}(1351.62-2318.26$ $\left.\mathrm{gC} \cdot \mathrm{m}^{-2} \cdot \mathrm{a}^{-1}\right)$. Regression analysis showed a linear relationship $\left(R^{2}=0.48\right)$ between the measured and simulated tree layer NPP values. NPP accounted for $30.2 \%(25.6 \%-32.9 \%)$ of GPP, while NEP accounted for $57.5 \%(48.1 \%-66.5 \%)$ of tree-layer NPP and $41.74 \%(37 \%-52 \%)$ of stand NPP. Soil respiration accounted for $77.0 \%$ of measured tree NPP and $55.9 \%$ of the measured stand NPP. NEE based on eddy covariance method was $12.97 \%$ higher than the observed NEP.

NPP, BGC, litter, annual biomass increment, flux

Net primary productivity (NPP) is an important indicator of energy flow and nutrient exchange in ecosystems. It supports nearly all heterotrophy (organisms that require preformed organic compounds for food) on the earth, including human beings ${ }^{[1]}$. Vitousek et al. ${ }^{[2]}$ estimated that $40 \%$ of NPP is consumed by human. Accurately estimating net primary productivity is critical to understand carbon dynamics within the atmosphere-vegetation-soil continuum and the response of terrestrial ecosystem to potential climate warming ${ }^{[3]}$. The main research methods on NPP are small-scale field investigations and macro-scale simulations. Most previous stud- ies were conducted with dimension analysis, stem analysis and flux measurement methods ${ }^{[4-6]}$. Regional NPP was mainly estimated by using the statistical models, process models and parametric models. Process models, with complete theoretical bases, could be applied to interpreting biological and biophysical mechanisms of plants ${ }^{[7]}$, such as $\mathrm{TEM}^{[8]}, \mathrm{BGC}^{[9,10]}$ and

\footnotetext{
Received February 20, 2008; accepted April 16, 2008 doi: $10.1007 / \mathrm{s} 11430-008-0075-7$

†Corresponding author (email: liuqijing@gmail.com)

Supported by the National Key Basic Research Special Foundation of China (Grant No. 2002CB4125), International Joint Research Project under Ministry of Science and Technology of China (Grant No. 2006DFB91920)
} 
BEPS $^{[11]}$. Individual plant biomass could be estimated using relative growth models. However, underground biomass, especially for fine roots, is often neglected ${ }^{[12]}$. It is difficult to accurately measure biomass in both canopy layer and substratum ${ }^{[13]}$; and biomass values are often underestimated $^{[14]}$.

At present, flux measurement by eddy covariance method is considered a powerful means for studying the mechanism of $\mathrm{CO}_{2}$ exchange between the atmosphere and ecosystems ${ }^{[4,5]}$. However, it is cost-intensive and is not necessarily as accurate as conventional approaches for biomass and soil carbon content, especially for sites with uneven topography ${ }^{[15]}$. For relatively short time scales, the net ecosystem production (NEP) is approximately equivalent to net ecosystem exchange (NEE) ${ }^{[16]}$. Comparative studies between NEP and NEE are useful to accurately estimate forest ecosystem carbon storage and to understand the causes of variation in annual carbon sequestration within and among sites ${ }^{[17]}$. In this study, we conducted an analysis by comparing data from field investigations with 3-a flux measurement results ${ }^{[6,18]}$.

Biome-BGC ${ }^{1)}$ is a widely used bio-geochemical model, which simulates the storage and dynamics of energy, water, carbon and nitrogen within vegetation and soil in terrestrial ecosystems. It is developed from a forest BGC model, which primarily describes forest carbon and nitrogen cycling ${ }^{[9,10]}$. The BEPS ${ }^{[11]}$ model also follows the principles of the BGC model. BGC is appropriate for simulation of NPP in artificial forest.

The estimation accuracy of models can be significantly affected by many factors, such as scaling up ${ }^{[19]}$, data acquisition and data quality ${ }^{[3]}$. Accurate and reliable data are essential for validating outputs derived by remote sensing. Uncertainty of forest NPP estimation is mainly introduced by three factors: sampling scheme, measuring method and calculating algorithms ${ }^{[20]}$. Partly because of this, the mechanism of carbon sink in forest ecosystem has not been satisfactorily clarified ${ }^{[21]}$. A potential breakthrough may rely on multi-scale observation and trans-scale modeling, e.g. quantitative simulation, helping us to understand the interactions between carbon cycling and ecosystem processes at different scales ${ }^{[15]}$. To accurately estimate NPP, it is essential to integrate multi-source data with long-term experiments.

In the early 1980s, slash pine (Pinus elliottii) was widely planted in south China to help preventing the severe degradation of ecosystems due to soil and water erosion. In terms of ecological restoration, it is significant to evaluate the contribution of the afforestation to environmental improvement on the basis of productivity, which is practical for ecosystem management and regional sustainable development. NPP can be measured through field survey, modeling simulation, as well as direct non-destructive measurement (eddy covariance method). Integrating different approaches could derive regional patterns of ecosystem productivity more precisely.

In this study, NPP of the slash pine plantation was measured and estimated at various scales, from individual trees to population, community and small watershed. The test site is located in Qianyanzhou Ecological Station in subtropical China. NPP calculated by Biome BGC model was compared with NEE by eddy covariance method. The DBH regression models were fitted by stem analysis with 59 trees and the annual net increment of community biomass was evaluated by field survey including the understory component. 12-year continuous measurement data on litter fall were also used for this study. The NPP of slash pine plantation from 1985 to 2005 in Qianyanzhou was simulated by BGC 4.2 22$]$ based on meteorological information and local tested parameters. A comparison among the results from the three approaches is carried on and the possible limitation for each method is discussed.

\section{Study site and methods}

\subsection{Site description}

Qianyanzhou Ecological Station, Chinese Academy of Sciences, is located in the red earth hilly area in Taihe County, Jiangxi Province $\left(26^{\circ} 44^{\prime} \mathrm{N}, 115^{\circ} 04^{\prime} \mathrm{E}\right)$. The total experimental area is $212.13 \mathrm{hm}^{2}$, where coniferous forest covers about $70 \%$. The elevation is about $100 \mathrm{~m}$. The monsoon climate dominates in this region. The mean annual temperature is $17.9^{\circ} \mathrm{C}$ and annual precipitation is $1489 \mathrm{~mm}$. The clear-sky duration per year is $1306 \mathrm{~h}$ and the solar radiation is $4349 \mathrm{MJ} \cdot \mathrm{m}^{-2}$. The soil is typical red earth, which is predominant in the entire subtropical region. The most common parent materials are red sandstone, sandy conglomerate, mudstone and alluvium ${ }^{[23]}$.

1) Biome-BGC Version 4.1.2 was provided by Peter Thornton at the National Center for Atmospheric Research (NCAR), and by the Numerical Terra Dynamic Simulation Group (NTSG) at the University of Montana. NCAR is sponsored by the National Science Foundation. 
The forest plantation began in 1985, including slash pine (Pinus elliottii) forest, Cunninghamia lanceolata forest, Pinus massoniana forest, Schima superba forest, Liquidambar formosana forest and Cirtus reticulata orchard. Dominant shrubs are Quercus fabri, Loropetalum chinense and Lespedeza formosa. Herbaceous species are mainly dominated by Arundinella setosa and Helicteres angustifolia. With canopy closure, shade-tolerant ferns are increasingly present, such as Adiantum flabellulatum, Blechnum oriental, Woodwardia japonica and Dryopteris championi ${ }^{[24]}$.

\subsection{Methods}

(1) Forest biomass survey. Twenty-nine slash pine forest plots, with an area no less than $20 \mathrm{~m} \times 20 \mathrm{~m}$, were investigated from July to September 2005. DBH of all trees was measured. Based on stem analysis, the relative growth models of biomass established previously ${ }^{[25]}$ are shown in Table 1. Root biomass of the canopy layer was measured by weighing all primary and lateral roots using 5 samples. The ratio between aboveground and underground biomass of trees was calculated; and the underground biomass was estimated based on this ratio.

Table 1 Biomass models for individual trees of P. elliottii at Qianyanzhou

\begin{tabular}{cccr}
\hline Items & Biomass models & $R^{2}$ & $N$ \\
\hline Leaves & $W_{\text {leaves }}=12.0741 D^{2.1515}$ & 0.735 & 19 \\
Branches & $W_{\text {branches }}=40.1892 D^{2.0074}$ & 0.713 & 19 \\
Stems & $W_{\text {stems }}=24.88 D^{2.5459}$ & 0.991 & 19 \\
Above ground & $W_{\text {above biomass }}=54.0477 D^{2.4295}$ & 0.959 & 19 \\
Roots & $W_{\text {roots }}=0.239 W_{\text {above-ground biomass }}$ & & 5 \\
\hline
\end{tabular}

(2) NPP observation for canopy layer. NPP of trees was directly measured in December 2004 by destructive harvesting. A total of 59 slash pines (mean DBH: 17.35 $\mathrm{cm})$ were analyzed with sliced discs.

Since the input parameter, DBH, for relative growth model must be with bark, a regression model ( $\mathrm{DBH}_{\text {over bark }}$ $\left.=-0.043+1.22 D B H_{\text {in bark, }} R^{2}=0.99\right)$ was fitted to estimate the over-bark DBH in the past years. NPP of the entire community, including shrubs, herbs, coarse roots and fine roots, was determined with the microanalysis $^{[26]}$ method:

$$
N P P=\Delta B=\frac{B_{2}-B_{1}}{t_{2}-t_{1}}+H+D,
$$

where $B_{1}$ is biomass $\left(\mathrm{g} \cdot \mathrm{m}^{-2}\right)$ in time $t_{1}$ and $B_{2}$ in time $t_{2}$; $H$ is predation by animals during $t_{2}-t_{1}$; the unit is $\mathrm{g} \cdot \mathrm{m}^{-2} \cdot \mathrm{a}^{-1} ; D$ is the amount of litter fall during $t_{2}-t_{1}$ and the unit is $\mathrm{g} \cdot \mathrm{m}^{-2} \cdot \mathrm{a}^{-1}$.

Animal-consumed biomass was ignored because the proportion is considered tiny and the amount is difficult to estimate.

DBH regression models, both in-bark and over-bark, were established to estimate $\mathrm{DBH}$ in the past years. Thus, the biomass of the canopy layer in the past was acquired. NPP of canopy layer was estimated with these components in addition to litter fall data.

(3) Biomass and productivity of understory. Biomass of shrubs and herbs was investigated by harvesting in 18 quadrates, each with a size of $1 \mathrm{~m} \times 1 \mathrm{~m}$.

To estimate the understory NPP, the ages of herbs and shrubs were arbitrarily assigned as 3 and 6 years, respectively. Fine-root $(0.28 \mathrm{~mm}<D<2 \mathrm{~mm})$ biomass was surveyed in 8 quadrate columns, each with a base area of $0.625 \mathrm{~m}^{2}$ and $0.40 \mathrm{~m}$ in depth. Roots were weighed after washing off soil. According to a previous report ${ }^{[27]}$, the turnover cycle of fine roots in subtropical coniferous forests is about 3 to 5 years, so the mean value of 4 years was adopted in this study.

(4) Litter fall observation. From 1992 to 2005 excluding 1997 and 1998, both fresh and dry weight of litter fall were measured monthly in 2 plots with 6 traps, each with a size of $1 \mathrm{~m}^{2}$. Data for 2 months in 1986 were lost due to mismanagement. All data gaps were filled with the observation data of adjacent years.

(5) Biome-BGC modeling. Biome-BGC ${ }^{[22]}$ is an ecological model that estimates fluxes and storage of energy, water, carbon and nitrogen for vegetation and soil components of terrestrial ecosystems. It requires meteorological data and soil and vegetation constants as input to simulate key ecosystem processes including photosynthesis, respiration and decomposition to yield ecosystem fluxes of energy and mass.

Flux estimated with the Biome-BGC model (http://www. ntsg.umt.edu) strongly depends on daily weather conditions. Site parameters include the description of geography and physics. Some physiological parameters were based on in-situ observation and the others were assigned as default. As to the meteorological data, it requires six categories of information: daily maximum temperature $\left(T_{\max },{ }^{\circ} \mathrm{C}\right)$, daily minimum temperature $\left(T_{\min },{ }^{\circ} \mathrm{C}\right)$, average daytime temperature $\left(T_{\text {day }},{ }^{\circ} \mathrm{C}\right)$, daily precipitation ( $\left.p r c p, \mathrm{~cm}\right)$, daytime average vapor pressure deficit (VPD, Pa) and daytime average short wave radiant flux density $\left(\mathrm{srad}, \mathrm{W} \cdot \mathrm{m}^{-2}\right)$. Because solar radiation was not observed until 1998 in the site, it 
has to be interpolated for the period of $1985-1998$. The Mountain Microclimate Model (MT-CLIM) (http://www. ntsg.umt.edu/) was adopted to estimated radiation. And an empirical model was introduced for deducing solar radiation based on the observed data from 1998 to 2004.

Precipitation and water vapor pressure create significant influences on radiation ${ }^{[28]}$. By adding maximum temperature and evaporation to the regression model, two localized models for Qianyanzhou were established. As a test, for the year 2005, the estimated values were and (3)) are shown as follows:

For rainy day,

$$
\begin{aligned}
& Q_{1}=-64.348+1.598 E+38.969 L+0.174 Q_{0} \\
&-0.868 P-6.649\left(S_{A} / S_{0}\right), \\
&\left(R=0.802, R^{2}=0.644, F=381.79, \text { Sig }<0.001\right) ;
\end{aligned}
$$

For no-rain day,

$$
\begin{gathered}
Q_{2}=112.451-2.752 E+43.497 L \\
+0.05385 Q_{0}+144.35\left(S_{A} / S_{0}\right), \\
\left(R=0.911, R^{2}=0.831, F=643.88, \text { Sig }<0.001\right) ;
\end{gathered}
$$

where $Q_{1}$ is the average solar radiation on rain day $\left(\mathrm{W} \cdot \mathrm{m}^{-2}\right), Q_{2}$ the average solar radiation on no-rain day $\left(\mathrm{W} \cdot \mathrm{m}^{-2}\right), Q_{0}$ the average daily astronomical radiation $\left(\mathrm{W} \cdot \mathrm{m}^{-2}\right), E$ the average daily water vapor pressure (hPa), $L$ the daily evaporation $(\mathrm{mm}), S_{\mathrm{A}} / S_{0}$ the sunshine percentage $(\%), S_{\mathrm{A}}$ the sunshine hours (h), $S_{0}$ the astronomical reasonable sunshine hour (h) and $P$ the precipi$\operatorname{tation}(\mathrm{mm})$.

\section{Results}

\subsection{Biomass and NPP distribution pattern of slash pine community}

The biomass of Pinus elliottii plantation was 10574

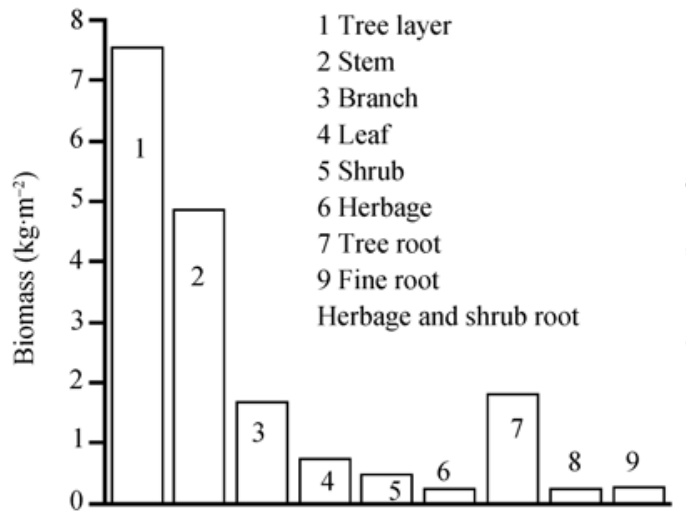

Figure 1 Biomass structure of $P$. elliottii forest. quite similar to observed values. The models (eqs. (2)

$\mathrm{g} \cdot \mathrm{m}^{-2}$ (Figure 1 ), with a ratio of 3.57 between aboveground and underground biomass. Accumulated litter fall was estimated to be $1631 \mathrm{~g} \cdot \mathrm{m}^{-2}$, with a ratio of 6.48 between biomass and litter accumulation. Biomass of the high canopy layer, shrub layer, herbaceous layer, tree roots, herbaceous and shrub roots and fine-roots $(0.28$ $\mathrm{mm}<$ roots $<5 \mathrm{~mm}$ ) were 7542, 480, 239, 1810, 230, 274 and $239 \mathrm{~g} \cdot \mathrm{m}^{-2}$ (as shown in Figure 1), respectively. Canopy layer biomass accounted for $71.33 \%$ of community biomass and $21.88 \%$ of root biomass. Fine root biomass accounted for $2.59 \%$ of community and $11.82 \%$ of below-ground biomass.

In the canopy layer, the ratio between aboveground biomass and root biomass was 4.3 , which was smaller than the ratio 7.64 measured in a slash pine forest in Guangxi, southwest China ${ }^{[29]}$. The ratio between the coarse root $(>5 \mathrm{~mm})$ biomass and fine-root biomass was 6.6 for the high tree layer and 8.3 for the community.

The NPP of the slash pine plantation was 1027.1 $\mathrm{g} \cdot \mathrm{m}^{-2} \cdot \mathrm{a}^{-1}$. The recent 5 -year mean NPP of the high tree layer (including tree roots), shrub layer (mean age 6), herbaceous layer (age 3), herbaceous and shrub roots (age 3$)$ and fine roots $(0.28 \mathrm{~mm}<$ roots $<2 \mathrm{~mm})$ measured $741,62.18,79.55,76.60$ and $68.38 \mathrm{~g} \cdot \mathrm{m}^{-2} \cdot \mathrm{a}^{-1}$, respectively. Tree-layer NPP accounted for $72.1 \%$ of community NPP. Herbaceous and shrub layers and fine roots contributed as much as $27.9 \%$ of the community NPP. In the canopy layer, the proportion of biomass was approximately identical with that of NPP.

\subsection{Empirical DBH regression models and NPP of canopy layer}

Based on stem analysis, 17 empirical DBH regression models were constructed as shown in Table 2.

DBH regression models showed high correlation coefficient $\left(R^{2}\right)$ among the consecutive years but it also

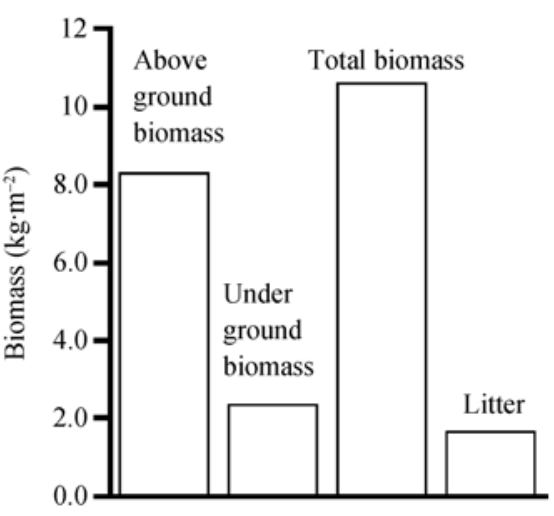


Table 2 Predictive equations for DBH of $P$. elliottii in different years

\begin{tabular}{|c|c|c|c|c|}
\hline Regression models & $R^{2}$ & $F$ & Mean & Std. \\
\hline$D B H_{1987}=0.06814 D_{2004}-0.862$ & 0.174 & 11.8 & 0.32 & 0.63 \\
\hline$D B H \_1988=0.167 D \_2004-1.724$ & 0.314 & 25.6 & 1.18 & 1.14 \\
\hline$D B H_{-1989}=0.288 D_{2004}-2.778$ & 0.482 & 52.2 & 2.23 & 1.59 \\
\hline$D B H_{1990}=0.384 D_{2004}-3.032$ & 0.568 & 73.7 & 3.64 & 1.95 \\
\hline$D B H_{-1991}=0.447 D_{2} 2004-2.88$ & 0.621 & 91.8 & 4.89 & 2.17 \\
\hline$D B H_{1992}=0.5 D_{2004}-2.597$ & 0.653 & 105.3 & 6.09 & 2.37 \\
\hline$D B H_{-} 1993=0.55 D_{2} 2004-2.27$ & 0.689 & 124.2 & 7.28 & 2.54 \\
\hline$D B H_{1} 1994=0.615 D_{2004}-2.075$ & 0.744 & 162.6 & 8.62 & 2.73 \\
\hline$D B H_{-1995}=0.664 D_{-2004}-1.781$ & 0.790 & 210.7 & 9.75 & 2.86 \\
\hline$D B H_{-} 1996=0.711 D \_2004-1.498$ & 0.833 & 280.1 & 10.85 & 2.98 \\
\hline$D B H_{-} 1997=0.766 D_{2004}-1.386$ & 0.869 & 371.9 & 11.92 & 3.15 \\
\hline$D B H_{-1998}=0.773 D \_2004-0.872$ & 0.896 & 484.8 & 12.55 & 3.13 \\
\hline$D B H_{-1999}=0.803 D_{2004}-0.617$ & 0.933 & 780.2 & 13.34 & 3.19 \\
\hline$D B H_{2} 2000=0.834 D_{2004}-0.428$ & 0.955 & 1188.2 & 14.06 & 3.27 \\
\hline$D B H_{2} 2001=0.887 D_{2004}-0.546$ & 0.980 & 2701.5 & 14.87 & 3.43 \\
\hline$D B H_{-2002}=0.942 D \_2004-0.645$ & 0.992 & 6851.3 & 15.72 & 3.62 \\
\hline$D B H_{2003}=0.973 D_{2004}-0.603$ & 0.996 & 15193.1 & 16.29 & 3.73 \\
\hline
\end{tabular}

showed a declining trend when the interval exceeded five years. The shorter the time interval, the more precise the model forecast.

For the canopy layer, annual litter fall was higher than biomass increment. But they were highly correlated $(Y=$ $1.19 X$, where $Y$ is litter fall and $X$ is biomass increment) with a correlation coefficient $\left(R^{2}\right)$ of 0.885 using 12 years' litter fall data. The biomass increment was highly correlated to litter fall in the following year, with an equation of $Y=1.26 X\left(R^{2}=0.683\right)$, where $Y$ is biomass increment and $X$ is litter fall in the following year.

Figure 2 indicates that both biomass increment and the litter fall showed an increasing trend with some fluctuations in the past 18 years. The carbon sequestration ability of the young plantation increased progressively, implying that reforestation is an efficient strategy

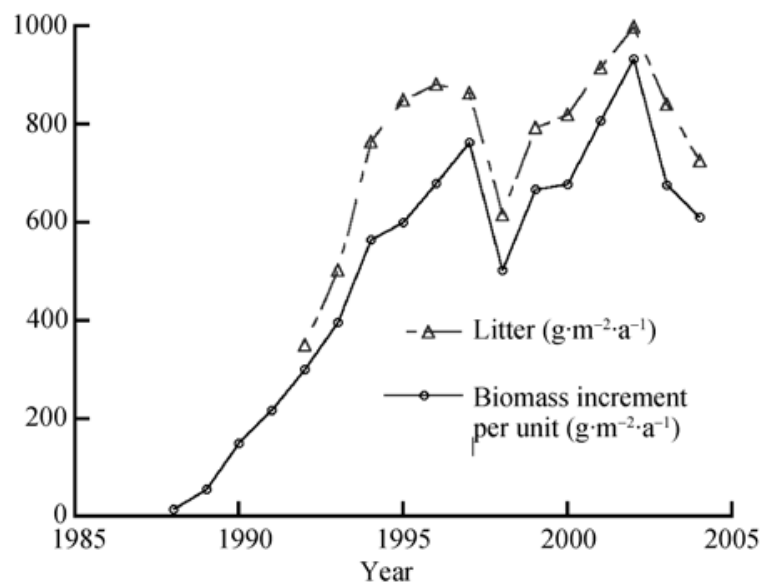

Figure 2 Inter-annual change of biomass and litter fall of $P$. elliottii forest. for carbon sink. From 1999 to 2004, the average annual biomass increment and litter fall were $741 \mathrm{~g} \cdot \mathrm{m}^{-2} \cdot \mathrm{a}^{-1}$ $\left(381.31 \mathrm{gC} \cdot \mathrm{m}^{-2} \cdot \mathrm{a}^{-1}\right)$ and $849 \mathrm{~g} \cdot \mathrm{m}^{-2} \cdot \mathrm{a}^{-1}\left(463 \mathrm{gC} \cdot \mathrm{m}^{-2} \cdot \mathrm{a}^{-1}\right)$, respectively, with a peak $\left(933 \mathrm{~g} \cdot \mathrm{m}^{-2} \cdot \mathrm{a}^{-1}\right)$ in 2002 . The biomass increment was quite similar in 1999 (666 $\left.\mathrm{g} \cdot \mathrm{m}^{-2} \cdot \mathrm{a}^{-1}\right)$ and in $2000\left(677 \mathrm{~g} \cdot \mathrm{m}^{-2} \cdot \mathrm{a}^{-1}\right)$ but sharply decreased in the drought years of 1998 and 2003. The highest litter fall was $999 \mathrm{~g} \cdot \mathrm{m}^{-2} \cdot \mathrm{a}^{-1}$ in 2002 .

\subsection{Simulation by BGC model}

Figure 3 shows the annual changes of NPP, gross primary production (GPP), maintenance respiration (MR) and max leaf area index (LAI) simulated by BGC over the period from 1985 to 2005 .

In order to better understand the relationship between quality of data and model parameters, four combinations of input data and parameter set were designed as follows:

(1) BM, all default parameters of BGC model and radiation data derived by MT-CLIM.

(2) BQ, all default parameters of BGC model and radiation data derived by empirical regression model for Qianyanzhou.

(3) QQ, part of eco-physiological constants measured by Qianyanzhou ecological Station and the radiation data derived by empirical regression model.

(4) QM, part of eco-physiological constants measured by Qianyanzhou ecological Station and the radiation data derived by MT-CLIM. 

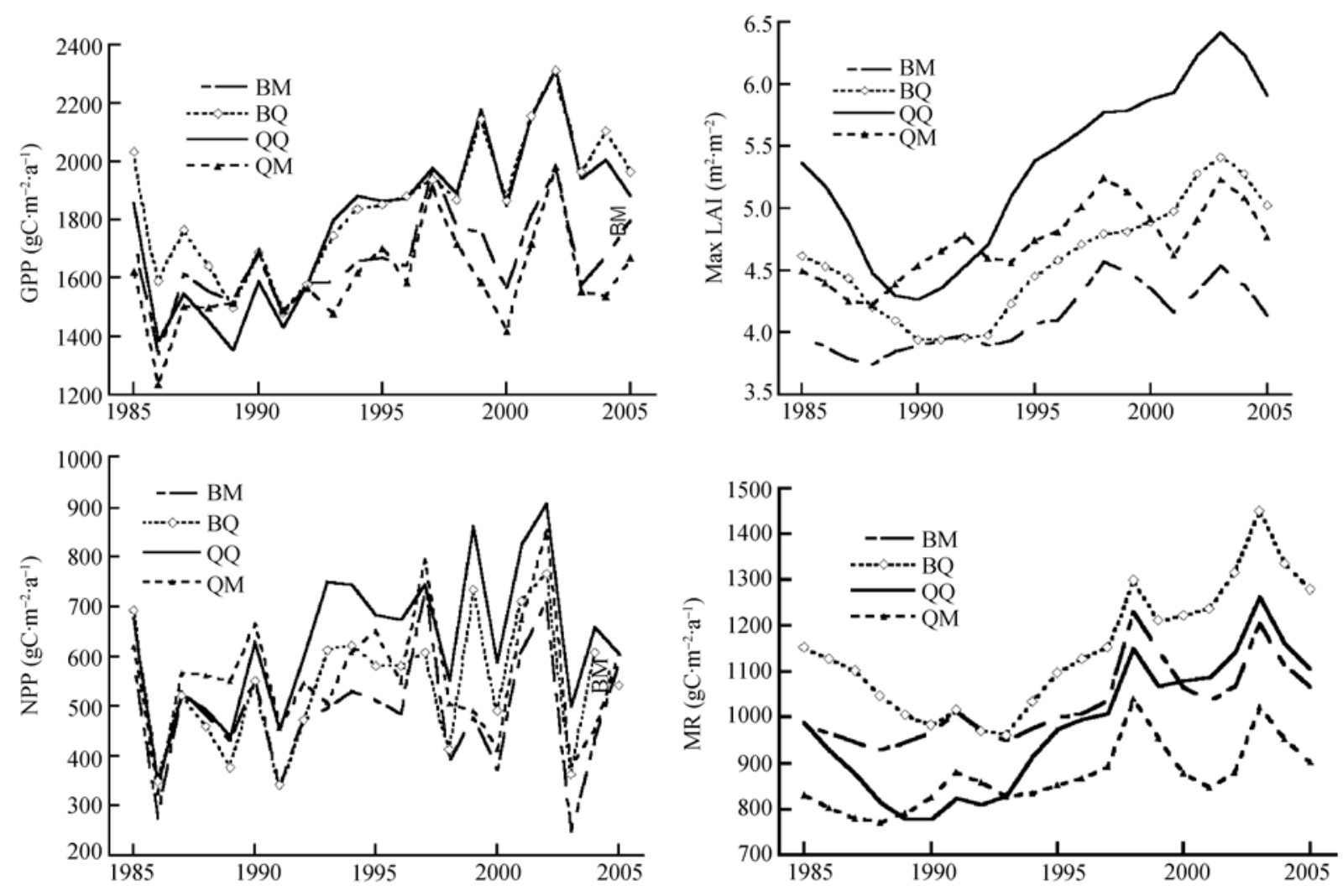

Figure 3 Ecosystem productivity simulated by BGC model.

Among these simulations, the results of the QQ design were the closest to the measured values. By combining BGC with QQ, the average NPP was estimated to be $630.88 \mathrm{~g} \mathrm{C} \cdot \mathrm{m}^{-2} \cdot \mathrm{a}^{-1}$ with minimum value in 1986 (343.31 $\left.\mathrm{g} \mathrm{C} \cdot \mathrm{m}^{-2} \cdot \mathrm{a}^{-1}\right)$ and maximum value in 2002 $\left(906.42 \mathrm{~g} \mathrm{C} \cdot \mathrm{m}^{-2} \cdot \mathrm{a}^{-1}\right)$. From 1985 to 2005 , average annual GPP, MAX LAI, MR, evapotranspiration and outflow were estimated to be $1800 \mathrm{~g} \mathrm{C} \cdot \mathrm{m}^{-2} \cdot \mathrm{a}^{-1}(1351.62$ $\left.-2318.26 \mathrm{~g} \mathrm{C} \cdot \mathrm{m}^{-2} \cdot \mathrm{a}^{-1}\right), \quad 5.32(4.2-6.41), 980.05$ $\left(776.52-1262.40 \mathrm{~g} \mathrm{C} \cdot \mathrm{m}^{-2} \cdot \mathrm{a}^{-1}\right), 110.56 \mathrm{~cm} \cdot \mathrm{a}^{-1}(84.18$ $\left.-133.18 \mathrm{~cm} \cdot \mathrm{a}^{-1}\right)$ and $37 \mathrm{~cm} \cdot \mathrm{a}^{-1}\left(0-98.82 \mathrm{~cm} \cdot \mathrm{a}^{-1}\right)$, respectively.

NPP, GPP and MAX LAI estimated by BGC in combination with QQ were the largest among all designs. As an example of NPP simulation, by comparing BM, MQ and QM with QQ, the average differences were $-21.77 \% \quad(-50.35 \%-0.01 \%),-13.75 \% \quad(-26.97 \%-$ $2.12 \%)$ and $-9.3 \%(-43.11 \%-25.53 \%)$, respectively.

Simulated GPP can be classified into 2 types according to ecophysiological constants. And simulated NPP, MR, and MAX LAI showed large variability under different parameter combinations.

\subsection{Model validation}

The carbon content of trunk, branch and leaf was $51.17 \%, 51.37 \%$ and $53.35 \%$, respectively, provided by the experimental station. The carbon densities in roots of shrubs and herbages were $54.53 \%$ and $68 \%{ }^{[30]}$. It was calculated at $51.46 \%$ for the total aboveground vegetation.

There was a linear relationship between simulated and measured NPP (Figure 4) $(Y=0.931 X$, where $Y$ is measured and $X$ is simulated NPP) and the correlation coefficient $\left(R^{2}\right)$ was 0.48 . By contrast, for the last 10 years, the relationship between the two could be expressed with a parabolic equation in the form of $Y=$ $0.00144-2.47 X+0.00215 X^{2}\left(R^{2}=0.53\right)$. The estimated NPP was principally consistent with the measured values, although the simulated curve showed less fluctuation compared with the actual process. The simulated NPP was $12.38 \%$ lower than measured NPP; but ranged between $-38.38 \%$ and $11.21 \%$.

Since the Biome BGC model is based on meteorological factors without considering stand age, the simulated NPP before 1995 was significantly higher than the real value (Figure 5). Apparently, within 8 years after 


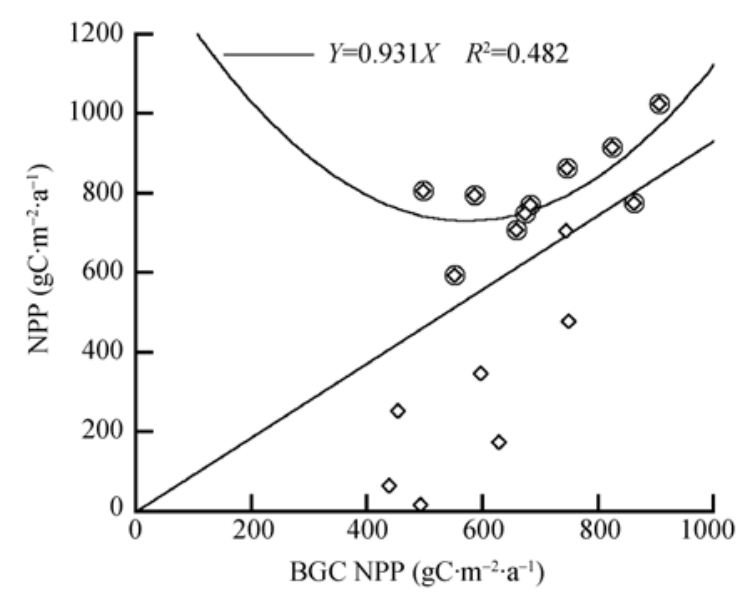

Figure 4 The comparison between BGC simulation and measured NPP.

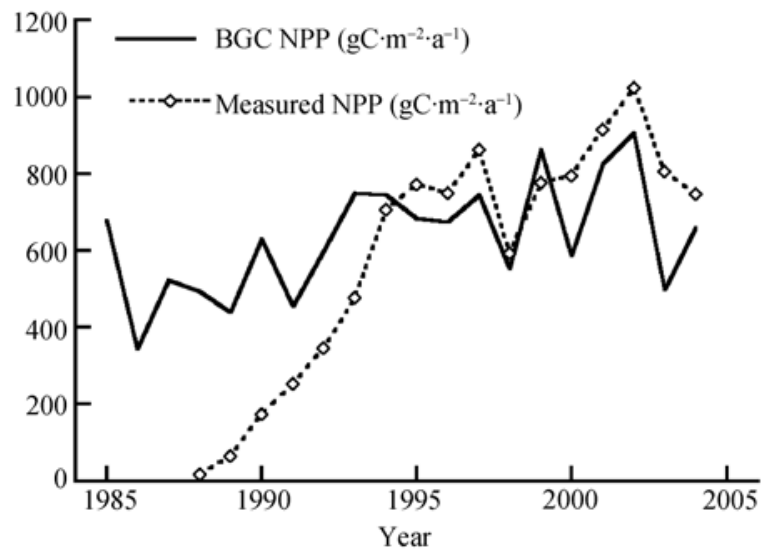

Figure 5 BGC-simulated and measured NPP from 1985 to 2004.

afforestation, the canopy layer was very sparse in coverage and the simulated results, therefore, greatly dif- fered from the measured values. The tested NPP consists of both underground and aboveground parts of the canopy layer only. NPP of shrubs and herbs (both aboveground and underground ) and fine roots, was 286 $\mathrm{g} \cdot \mathrm{m}^{-2} \cdot \mathrm{a}^{-1}$ in total, or $38.69 \%$ of the tree-layer NPP.

The measured NPP of the forest stand was significantly higher than the value simulated by the BGC model. From a global perspective, as a result of the control of subtropical high pressure, this region has a relatively dry climate, which causes low primary productivity. In the test site, however, typical subtropical monsoon climate is predominant and the air mass is moister than most areas along this latitude. Because monsoon climate is not considered in the algorithm, the simulation presented some inconsistency with measured values.

The NEE observed by eddy covariance was $12.97 \%$ (on average) higher than measured NEP from 2003 to 2005 (Table 3). NEE in 2004 was very close to measured NEP, with a difference of only $73 \mathrm{~g} \mathrm{C} \mathrm{m}^{-2} \cdot \mathrm{a}^{-1}$, which is close to international mainstream error sources, $\pm 50 \mathrm{~g} \mathrm{C} \mathrm{m}^{-2} \cdot \mathrm{a}^{-1[31]}$. Measured NPP was $22.55 \%$ higher than the simulated value.

Although it was extremely dry, NPP was the highest in 2003. A possible reason for this is that the NPP of herbages, shrubs and fine roots as constants was large in addition to a dramatic increase in litter fall. Besides, the BGC model does not consider the time lag of ecosystem processes.

Table 3 Carbon budget of the plantations in Qianyanzhou $\left(\mathrm{g} \mathrm{C} \cdot \mathrm{m}^{-2} \cdot \mathrm{a}^{-1}\right)$

\begin{tabular}{|c|c|c|c|c|c|}
\hline Year & & 2003 & 2004 & 2005 & Mean \\
\hline \multirow{3}{*}{$\mathrm{EC}^{\mathrm{a})}$} & NEE & 387.2 & 423.8 & 691.6 & 500.9 \\
\hline & $\mathrm{RE}$ & 1223.3 & 142 & 1226.7 & 1297.3 \\
\hline & GEE & 1610.4 & 1865.9 & 1918.2 & 1798.2 \\
\hline \multirow{3}{*}{$\begin{array}{c}\text { BGC } \\
\text { modeling }\end{array}$} & NPP & 497.1 & 659.2 & 605.3 & 587.2 \\
\hline & GPP & 1941.2 & 2003.5 & 1881.6 & 1942.1 \\
\hline & MR & 1262.4 & 1161.3 & 1105 & 1176.3 \\
\hline \multirow{4}{*}{$\begin{array}{l}\text { Forest } \\
\text { survey }\end{array}$} & Canopy layer NPP & 806.9 & 747.6 & $720.2^{\mathrm{e})}$ & 758.2 \\
\hline & Litter per year & 459.1 & 395.3 & 380.9 & 411.8 \\
\hline & $\begin{array}{l}\text { Annual Biomass } \\
\text { Increment of canopy layer }\end{array}$ & 347.7 & 352.3 & 339.3 & 346.4 \\
\hline & $\begin{array}{l}\text { Forest } \\
\text { communities } \\
\mathrm{NPP}^{\mathrm{c})}\end{array}$ & 1092.9 & 1033.6 & 1006.2 & 1044.2 \\
\hline \multirow{3}{*}{$\begin{array}{c}\text { Soil } \\
\text { respiration }^{\text {b) }}\end{array}$} & $\mathrm{NEP}^{\mathrm{d})}$ & & 497.1 & 374.7 & 435.9 \\
\hline & $\begin{array}{l}\text { With litter } \\
\text { covered }\end{array}$ & & 536.5 & 631.5 & 584 \\
\hline & No litter covered & & 327.5 & 394 & 360.8 \\
\hline
\end{tabular}

a) EC (by eddy covariance) ${ }^{1)}$; b) Soil respiration by static observation ${ }^{[32]}$; c) Community NPP equal to tree-layer NPP plus the rest items (286 $\left.\mathrm{g} \mathrm{C} \cdot \mathrm{m}^{-2} \cdot \mathrm{a}^{-1}\right)$; d) $\mathrm{NEP}=$ community NPP-soil respiration; e) Net increment in 2005 estimated based on litter fall.

1) Liu Y F. Flux observation and carbon budget in Qianyanzhou (no published). 2008 
Soil respiration was active with a yearly average of $584 \mathrm{~g} \mathrm{C} \cdot \mathrm{m}^{-2} \cdot \mathrm{a}^{-1}$. Ecosystem respiration $(\mathrm{Re})$ observed by the flux tower was similar to maintenance respiration (MR) simulated by the BGC model, with an average difference of $9.3 \%(3.1 \%-19.4 \%)$.

Based on the simulation, the pattern of productivity is summarized as follows. NPP and MR accounted for $30.2 \%(25.6 \%-32.9 \%)$ and $60.5 \%$ of GPP, respectively. NEP accounted for $57.5 \%(48.1 \%-66.5 \%)$ of tree-layer NPP and $41.74 \%(37 \%-52 \%)$ of total stand NPP. Soil respiration was $77.0 \%$ of measured tree NPP and $55.9 \%$ of measured community NPP. Soil respiration was approximately the same as litter fall, with the ratio between the two being $1.05(0.99-1.26)$.

\section{Discussion}

Based on investigation and long-term observation, carbon stock and the NPP pattern of slash pine plantation were analyzed and the growing process of NPP over 21 years was simulated with Biome BGC.

Preliminary study results are as follows:

(1) From 1999 to 2004, the average annual growth rate and the litter fall were $741 \mathrm{~g} \cdot \mathrm{m}^{-2} \cdot \mathrm{a}^{-1}(381.31$ $\left.\mathrm{g} \mathrm{C} \cdot \mathrm{m}^{-2} \cdot \mathrm{a}^{-1}\right)$ and $849 \mathrm{~g} \cdot \mathrm{m}^{-2} \cdot \mathrm{a}^{-1}\left(463 \mathrm{~g} \mathrm{C} \cdot \mathrm{m}^{-2} \cdot \mathrm{a}^{-1}\right)$, respectively. There was significant correlation between annual litter fall and annual biomass increment and litter was 1.19 times greater than the biomass increment of living trees. From 1985 to 2005, NPP and GPP by BGC modeling were $630.88\left(343.31-906.42 \mathrm{~g} \mathrm{C} \cdot \mathrm{m}^{-2} \cdot \mathrm{a}^{-1}\right)$ and $1800 \mathrm{~g} \mathrm{C} \cdot \mathrm{m}^{-2} \cdot \mathrm{a}^{-1}\left(1351.62-2318.26 \mathrm{~g} \mathrm{C} \cdot \mathrm{m}^{-2} \cdot \mathrm{a}^{-1}\right)$, respectively.

(2) A linear relationship $\left(R^{2}=0.48\right)$ exists between measured and simulated NPP of the canopy layer.

(3) NPP accounted for $30.2 \%(25.6 \%-32.9 \%)$ of GPP. NEP accounted for $57.5 \%(48.1 \%-66.5 \%)$ of canopy layer NPP and $41.74 \%(37 \%-52 \%)$ of stand NPP. Soil respiration accounted for $77.0 \%$ of measured tree NPP; and $55.9 \%$ of measured stand NPP.

(4) NEE by eddy covariance was $12.97 \%$ higher than observed NEP. The measured NPP of forest communities was significantly higher than the one simulated by the BGC model.

(5) Since time lag is little considered in the BGC model, especially at a regional scale, the simulated values may be lower than actual values.
Ecosystem carbon fluxes can be measured continuously using eddy covariance techniques and the relationship between carbon fluxes and environmental variables can be acquired. This is significant for clarifying the ecosystem process and its coupling mechanism with environmental variables. By contrast, traditional methods of stand survey only focus on plants and the contribution to carbon storage can be specifically identified.

Definitely, there is inconsistency between the two approaches. NEE by eddy covariance was slightly higher than NEP as measured by biomass survey. On one hand, in the process of calculating forest NEP from measured NPP, soil respiration included the root respiration and soil microbial respiration. We need to further distinguish these two parts of respiration. On the other hand, it was impossible to accurately measure fine-root turnover rate, so the survey values for fine root NPP may be underestimated. Thus, the value of NEP has been underestimated to some extent.

BGC model simulation was apparently affected by the input ecophysiological constants. Overall, it was difficult to obtain all the measured parameters. BGC model needs as many as 34 types of parameters, some of which are very difficult to collect and have not even been studied in China. The data quality was another factor, which may have affected simulation results. Although meteorological data have been observed at Qianyanzhou Biological Station continuously over 20 years, radiation, for example, had not been observed until the past 8 years. Many data points had to be interpolated. NPP simulated by BEPS based on meteorological data released by the National Center for Atmospheric Research (NCAR) was 15\% lower than that simulated by the same model with data from Japan Meteorological Association (JWA) ${ }^{[3]}$. The results of this study showed that relative errors of estimated NPP in different combinations were even greater than those from different sources of data.

The mean aboveground biomass was $256 \mathrm{~g} \cdot \mathrm{m}^{-2}(227$ $\left.-294 \mathrm{~g} \cdot \mathrm{m}^{-2}\right)^{[23]}$ in 1983 , when the station was established before afforestation, and it turned out to be 8261 $\mathrm{g} \cdot \mathrm{m}^{-2}$ in 2005 , increasing 32.3 times. The mean annual biomass increment was $348 \mathrm{~g} \cdot \mathrm{m}^{-2}$. So the forest was evidently functioning as a carbon sink. The biomass of coarse roots $(>5 \mathrm{~mm})$ was over 8.3 times the fine root biomass and this ratio was slightly smaller compared to that of a European beech (Fagus sylvatica) forest (10 
times) ${ }^{[33]}$. In this study, the NPP of fine roots accounted for $6.67 \%$ of the total community NPP, which was lower than that of a 40-a Picea abies forest in Norway $(13 \%)^{[34]}$. With forest growth, the proportion of fine roots is expected to increase. The turnover rate of fine roots is significantly faster than that of coarse roots, which is currently a popular topic in ecosystem studies yet difficult to quantify ${ }^{[35,36]}$.

The growing diameter at breast height $(\mathrm{DBH})$ can be directly measured in the field. Therefore, it is a suitable way to study NPP of mixed forest by monitoring tree diameter and collecting litter fall. And the results can be compared with NEE values observed by eddy covariance methods ${ }^{[37]}$. It is possible to reduce the system error by stem analysis. However, self-thinning of forest must be considered when evaluating carbon balance. Based on data acquired in $1990^{[38]}, 1994^{[39]}, 1997^{[40]}, 1999^{[41]}$ and the present survey, the process of forest thinning was simulated as shown in Figure 6. Due to dieback, litter fall decreased to $0.11 \mathrm{~g} \cdot \mathrm{m}^{-2}$ (about $0.03 \%$ of annual forest biomass increment), which was not included in the calculation of NPP. Thus, accurate estimation of NPP should be based on long-term monitoring with a uniform standard.

Simulations with 17 ecosystem process models demonstrated that global and regional NPP is sensitive to available water ${ }^{[19]}$. It is estimated that the proportion of vegetation on the globe with growth limited by water availability is $40 \%$, and that limited by temperature and radiation is $33 \%$ and $27 \%$, respectively ${ }^{[42]}$.

After reviewing 49 studies on forest NPP over 55 years, we found that less than $7 \%$ of forests were in severely water-limited systems ${ }^{[43]}$. This paper shows that the NPP model simulation was sensitive to water conditions as shown in Figure 7. There were two drought years (1986 and 2003), and the simulated values were accordingly smaller. The difference in NPP from 2003 to 2004 was $162 \mathrm{~g} \mathrm{C} \cdot \mathrm{m}^{-2} \cdot \mathrm{a}^{-1}$, according to simulation. In addition, the differences between simulation and tested results for the 2 years were not significant, being 59 and $36 \mathrm{~g} \mathrm{C} \cdot \mathrm{m}^{-2} \cdot \mathrm{a}^{-1}$, respectively.

We can conclude that the ecosystem had a buffering effect under extreme weather conditions. Therefore, the time-lag effect should also be taken into account when NPP is simulated by process model. "The combined and interaction effects of temperature, radiation and precipitation change with the positive effect of $\mathrm{CO}_{2}$ concentra- tion, the negative effects of $\mathrm{O}_{3}$ and other pollutants. And the present positive effects on NPP would not be elucidated with experimental manipulation of one or a few factors at a time" ${ }^{,[43]}$. Long-term field monitoring and flux measurement are essential for obtaining robust information on carbon cycling. Furthermore, the study of future carbon cycling will mostly rely on remote sensing data on regional scales ${ }^{[20]}$. The development of relevant models is of great help to measuring carbon budgets by combining remote sensing images and ecological algorithms ${ }^{[44]}$.

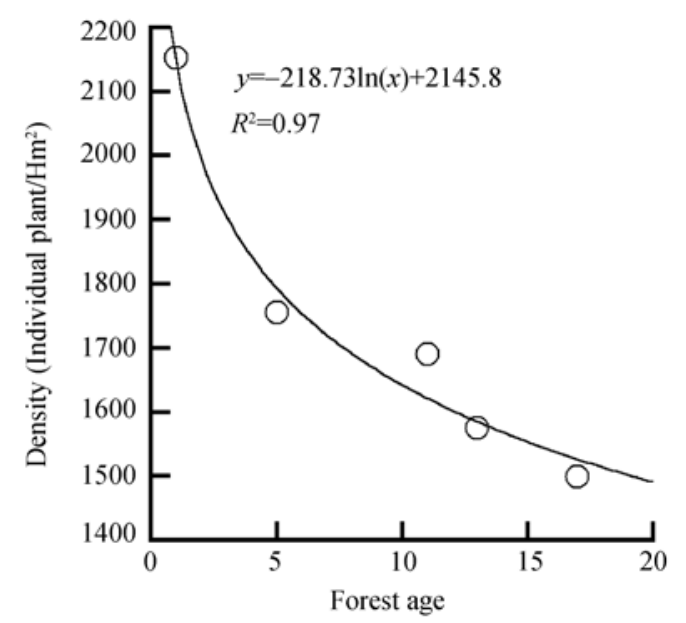

Figure 6 The relationship between forest age and forest density.

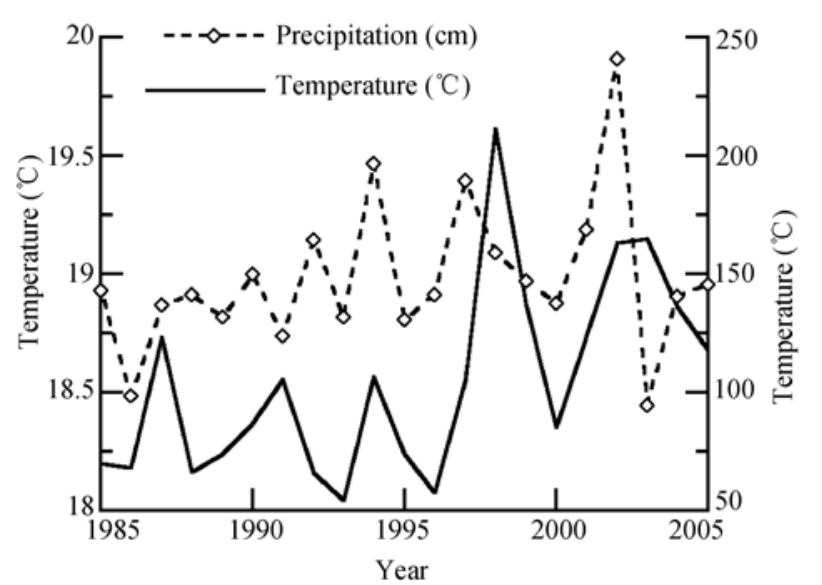

Figure 7 The annual mean temperature $\left({ }^{\circ} \mathrm{C}\right)$ and annual mean precipitation(cm) from 1985 to 2005 in QYZ.

At present, there is no model that fully considers the role of subtropical monsoon climate in this region. The NPP was higher in this region than in other areas at similar latitudes. Trees showed vigorous growth in February, April, May and August. The regression coefficient between volume increment and maximum temperature in May was 0.6, while the coefficients in $\mathrm{Au}-$ 
gust between volume increment and precipitation, evaporation and air temperature were $0.44,0.44$ and -0.39 , respectively.

Changes in carbon sequestration ${ }^{[45]}$ and the soil carbon pool ${ }^{[46]}$ in Qianyanzhou ecological Station were recently reported, so that we did not specifically discuss soil carbon here.

In brief, ecosystem carbon cycling research should include robust data from long-term observation as a

1 Field C B. Perspectives on global change: sharing the garden. Science, 2001, 294: 2490-2491

2 Vitousek P M, Ehrlich P R, et al. Human Appropriation of the Products of Photosynthesis. BioScience, 1986, 36: 368-373

3 Matsushita B, Xu M, Chen J, et al. Estimation of regional net primary productivity (NPP) using a process-based ecosystem model: How important is the accuracy of climate data? Ecol Model, 2004, 178(3-4): $371-388$

4 Wang $\mathrm{H}$, Saigusa $\mathrm{N}$, Yamamoto $\mathrm{S}$, et al. Net ecosystem $\mathrm{CO}_{2}$ exchange over a larch forest in Hokkaido, Japan Atmos Environ, 2004, 38 (40): $7021-7032$

5 Wang $\mathrm{H}$, Saigusa N, $\mathrm{Zu} \mathrm{Y}$, et al. Response of $\mathrm{CO}_{2}$ flux to environmental variables in two larch forest ecosystems in East Asia. Phyton-Ann Rei Bot, 2005, 45(4), 339-346

6 Liu Y F, Song X, Yu G R, et al. Seasonal variation of CO2 flux and it environmental factors in evergreen coniferous plantation. Sci China Ser D-earth Sci, 2005, 48(Supp. I ): 123-133

7 Li S H, Niu Z, Li B C. Study on remote sensing driving factors of NPP process model. Res Soil Water Conservation (in Chinese with English abstract), 2005, 12(3): 120-123

8 Melillo J M, Mcguire A D, Kicklighter D W, et al. Global climate change and terrestrial net primary production. Nature, 1993, 363: $234-240$

9 Running S W, Coughlan C A. A general model of forest ecosystem processes for regional applications I. Hydrologic balance, canopy gas exchange and primary production processes. Ecol Model, 1988, 42(2): $125-154$

10 Running S W, Gower S W. FOREST-BGC, A general model of forest ecosystem processes for regional applications. II. dynamic carbon allocation and nitrogen budgets. Tree Physiol, 1991, 9: 147-160

11 Liu J, Chen J M, Cihlar J, et al. A process-based boreal ecosystem productivity simulator using remote sensing inputs. Remote Sens Environ, 1997, 62(2): 158-175

12 Clark D A, Brown S, Kicklighter D W, et al. Measuring net primary production in forests : concepts and field methods. Ecol Appl, 2001, 11(2): $356-370$

13 Hoffmann C W, Usoltsev V A. Tree-crown biomass estimation in forest species of the Ural and of Kazakhstan. Forest Ecol Manag, 2002, 158: 59-69

14 Clark D A, Brown S, Kicklighter D W, et al. Net primary production in tropical forests: an evaluation and synthesis of existing field data. Ecol Appl, 2001, 11(2): 371-384 fundamental approach. Various methods describing ecosystem processes and function, such as multi-scale simulation and observation, are helpful to ecosystem management and understanding of global environment issues.

The authors thank Chen YongRui and Liu YunFen for very helpful comments and suggestions and Liu YingChun who joined the field survey. Special thanks go to Dr. Laura Ediger who helped with the revision of this manuscript.

15 Cao M K, Yu G R, Liu J Y, et al. Multi-scale observation and cross-scale mechanistic modeling on terrestrial ecosystem carbon cycle. 2005, Sci China Ser D-earth Sci, 2005, 48(Supp. I ): 17-32

16 Chapin F S Ш, Matson P A, Mooney H A. Principles of Terrestrial Ecosystem Ecology. New York: Springer-Verlag, 2002

17 Curtis P S, Hanson P J, Bolstad P, et al. Biometric and eddy-covariance based estimates of annual carbon storage in five eastern North American deciduous forests. Agri Forest Meteor, 2002, 113: 3-19

18 Liu Y F, Yu G R, Wen X F, et al. Seasonal dynamics of $\mathrm{CO}_{2}$ fluxes from subtropical plantation coniferous ecosystem. Sci China Ser D-Earth Sci, 2006, 49(Supp. II ): 99-109

19 Cramer W, Kicklighter D W, Bondeau A, et al. The. Participants Of. The. Potsdam NPP Model Intercomparison. Comparing global models of terrestrial net primary productivity (NPP): Overview and key results. Global Change Biol, 1999, 5(1): 1-15

20 Brown S. Measuring carbon in forests: Current status and future challenges. Environ Pollut, 2002, 116: 363-372

21 IPCC. Climate Change 1995: The Science of Climate Change. UK: Cambridge University Press, 1996

22 Thornton P E, Law B E, Gholz H L, et al. Modeling and measuring the effects of disturbance history and climate on carbon and water budgets in evergreen needleleaf forests. Agri Forest Meteor, 2002, 113(1-4): $185-222$

23 Scientific Investigation Team of Chinese Academy of Sciences for Southern Mountainous Areas, Management Office of Natural Resources in Ji'an Prefecture of Jiangxi Province. Management and Development of Red Hilly Area Experimental Study in Qianyanzhou (in Chinese). Beijing: Science Press, 1989. 1-23

24 Liu Q J, Hu L L, Li X R. Plant diversity in Qianyanzhou after 20 years of small watershed treatment. Acta Phyt Sin (in Chinese with English abstract), 2005, 29(5), 766-774

25 LI X R, Liu Q J, Chen Y R, et al. Aboveground biomass of three conifers in Qianyanzhou plantation. Chin J Appl Ecol (in Chinese with English abstract), 2006, 17(8), 1382-1388

26 Dong M. Survey and Analysis of Terrestrial Biological Community (in Chinese). Beijing: Chinese Standard Publishing Company, 1996, $59-81$

27 Zhang X Q, Wu K H. Fine-root production and turnover for forest ecosystem. Sci Silv Sin (in Chinese with English abstract), 2003, 7(3): $126-138$

28 Zhang Y, Zhao S Q. A discussion about the approach to estimate daily 
solar radiation. Meteorol Monthly (in Chinese), 1991, 17(10): 52-53

29 Fang X, Tian D L, Xiang W H, et al. On carbon accumulation, distribution of different densities in slash pine plantation. J Zhejiang Forestry College (in Chinese with English abstract). 2003, 20(4): $374-379$

30 Yuan X H. Effects of land use on terrestrial ecosystem organic C in red soil hilly region in subtropical China. Dissertation for the Master Degree. Beijing: Institute of Geographic Sciences and Natural Resources Research, Chinese Academy of Sciences, 1999. 1-72

31 Baldocchi D D. Assessing the eddy covariance technique for evaluating carbon dioxide exchange rates of ecosystems: past, present and future. Global Change Biol, 2003, 9: 479-492

32 Sheng W Q. Carbon budgets of coniferous plantations in Qianyanzhou experimental station, Jiangxi, China. Dissertation for the Doctor Degree. Beijing: Beijing Forest University, 2006, 100-101

33 Scarascia-Mugnozza G, Bauer G A, Persson H, et al. Tree biomass, growth and nutrient pools. In: Schulze, E D, ed. Carbon and Nitrogen Cycling in European Forest Ecosystems. Berlin: Springer-Verlag, 2000

34 Ostonen I, Lǒhmus K, Pajuste K. Fine root biomass, production and its proportion of NPP in a fertile middle-aged Norway spruce forest: comparison of soil core and ingrowth core methods. Forest Ecol Manag, 2005, 212: 264-277

35 Copley J. Ecology goes underground. Nature, 2000, 406: 452-454

36 Matamala R, Gonzalez-Meler M A, Jastrow J D, et al. Impacts of fine root turnover on forest NPP and soil C sequestration potential. Science, 2003, 302: $1385-1387$

37 Ohtsuka T, Akiyama T, Hashimoto Y, et al. Biometric based estimates of net primary production (NPP) in a cool-temperate deciduous forest stand beneath a flux tower. Agri Forest Meteor, 2005, 134: 27-38
38 Chen Y R. Forestry status and evaluation in Qianyanzhou station. In: Cheng T, eds. Eco-system Restoration and Agricultural Sustainable Development in Red Soil Hilly Region (the first series). Beijing: Seismic Press, 1993. 90-94

39 Wang X J. Monitoring and evaluation of soil changes under land use of different patterns at a small regional level in south China Dissertation for the Doctoral Degree. Nanjing: The Institute of Soil Science, Chinese Acedamy of Sciences, 1995

40 Chen Y R, Li F. Study on the accumulation, transfer and distribution of the nutrient elements in the artificial forest of Pinus ellottii. Resour Sci (in Chinese with English abstract), 1998, 20(Supp): 19-55

41 Cai Y L, Li F, Li J Y, et al. A study on rainfall chemistry of artificial forests in red earth hilly area. J Nat Resour (in Chinese with English abstract), 2003, 18(1): 99-104

42 Nemani R R, Keeling C D, Hashimoto H, et al. Climate-driven increases in global terrestrial net primary production from 1982 to 1999 . Science, 2003, 300: 1560-1563

43 Boisvenue C, Running S W. Impacts of climate change on natural forest productivity-evidence since the middle of the 20th century Global Change Biol, 2006, 12(5): 862-882

44 Plummer S E. Perspective on combining ecological process models and remotely sensed data. Ecol Model, 2000, 129: 169-186

45 Huang M, Ji J J, Li K R, et al. The ecosystem carbon accumulation after conversion of grasslands to pine plantations in subtropical red soil of South China. Tellus, 2007, 59B: 439-448

46 Wang S Q, Liu J Y, Yu G Y, et al. Effects of land use change on the storage of soil organic carbon - A case study of the Qianyanzhou Forest Experimental Station in China. Climate Change, 2004, 67: $247-255$ 